\title{
Gametófitos de Pleurosorus papaverifolius (Kunze) Fée (Aspleniaceae) y Cheilanthes glauca (Cav.) Mett. (Pteridaceae), dos helechos rupícolas sudamericanos
}

\author{
Jose María Gabriel y Galán ${ }^{1,2}$ y Carmen Prada ${ }^{1}$
}

Recibida 16/05/2008. Aceptado 2/12/2008

RESUMO - (Gametófitos de Pleurosorus papaverifolius (Kunze) Fée (Aspleniaceae) e Cheilanthes glauca (Cav.) Mett. (Pteridaceae), dois fetos rupestres sul-americanos). O objetivo deste trabalho foi estudar a germinação de esporos, o desenvolvimento morfológico dos gametófitos e a expressão sexual de dois pteridófitas sul-americanos rupestres: Pleurosorus papaverifolius (Kunze) Fée. e Cheilanthes glauca (Cav.) Mett. Os esporos mostraram uma germinação vigorosa, e foram alcançadas percentagens relativamente altas de germinação (>70\%) em menos de três semanas. Pleurosorus papaverifolius desenvolveu uma fase filamentosa de crescimento lento, com células grossas e inchadas que davam ao gametófito um aspecto algo arredondado; de forma contrária, em Cheilanthes glauca esta etapa foi efémera e rapidamente se passou à fase laminar. As formas pré sexuais tinham o aspecto cordado em ambas as espécies, mas em Pleurosorus papaverifolius desenvolveram-se, além disso, abundantes protalos alargados de maior tamanho. Enquanto que os protalos de Cheilanthes glauca foram não tricomados, os de Pleurosorus papaverifolius apresentaram numerosos tricomas unicelulares tanto marginais como superficiais. Ambos os pteridófitas se diferenciaram também na sua expressão sexual, que começou com o desenvolvimento de anterídios em Pleurosorus papaverifolius e de arquegónios em Cheilanthes glauca. Em Pleurosorus papaverifolius nunca se observaram gametófitos femininos, mas sim abundantes bissexuais. Cheilanthes glauca manteve durante muito tempo um número similar de gametófitos femininos e masculinos, produzindo unicamente um reduzido número de protalos bissexuais.

Palavras-chave: Cheilanthes, Gametófitos, Pleurosorus, rupestre, Sul-américa

RESUMEN - (Gametófitos de Pleurosorus papaverifolius (Kunze) Fée (Aspleniaceae) y Cheilanthes glauca (Cav.) Mett. (Pteridaceae), dos helechos rupícolas sudamericanos). En este trabajo se estudia la germinación de la espora, el desarrollo morfológico de los gametófitos y la expresión sexual de dos pteridófitos sudamericanos rupícolas: Pleurosorus papaverifolius (Kunze) Fée. y Cheilanthes glauca (Cav.) Mett. Las esporas mostraron una germinación vigorosa, y se alcanzaron porcentajes relativamente altos de germinación (>70\%) en menos de tres semanas. Pleurosorus papaverifolius desarrolló una fase filamentosa de lento crecimiento, con células gruesas e hinchadas que daban al gametófito un aspecto algo redondeado; por el contrario, en Cheilanthes glauca esta etapa fue efímera y rápidamente se dio paso a la fase laminar. Las formas presexuales fueron cordadas en ambas especies, pero en Pleurosorus papaverifolius se desarrollaron, además, abundantes protalos alargados de mayor tamaño. Mientras que los protalos de Cheilanthes glauca fueron desnudos, los de Pleurosorus papaverifolius presentaron numerosos tricomas unicelulares tanto marginales como superficiales. Ambos pteridófitos difirieron también en su expresión sexual, que comenzó con el desarrollo de anteridios en Pleurosorus papaverifolius y de arquegonios en Cheilanthes glauca. En Pleurosorus papaverifolius nunca se observaron gametófitos femeninos, pero sí abundantes bisexuales. Cheilanthes glauca mantuvo durante largo tiempo un número similar de gametófitos femeninos y masculinos, produciendo solamente un reducido número de protalos bisexuales.

Palabras clave: Cheilanthes, Gametófitos, Pleurosorus, rupícola, Sudamérica

\section{Introducción}

Pleurosorus Fée (Aspleniaceae) es un género que comprende cuatro especies: Pleurosorus hispanicus (Cosson) C. V. Morton; Pleurosorus papaverifolius (Kunze) Fée; Pleurosorus rutifolius (R. Br.) Fée y Pleurosorus subglandulosus (Hook. \& Grev.) Tindale. El género muestra una distribución fundamentalmente austral, pero considerablemente disyunta, hecho ya puesto de manifiesto por autores clásicos (Christ 1910), pero que continúa preocupando a algunos más modernos (Given 1972; Rodríguez 1976; Salvo et al. 1982; Kramer 1993): Pleurosorus tiene representantes en Australia y Nueva Zelanda (Pleurosorus rutifolius y Pleurosorus subglandulosus), Chile y Argentina (Pleurosorus papaverifolius), y España, Portugal, Marruecos y Argelia (Pleurosorus hispanicus).

La especie estudiada aquí, Pleurosorus papaverifolius, parece mostrar una cierta variación morfológica en el esporófito, pues se han descrito algunas variedades (Villagrán \& Mesa 1971).
Por su parte, Cheilanthes Sw. (Pteridaceae) es un género que comprende unas 150-200 especies. Su distribución es cosmopolita, si bien se concentra en regiones semiáridas de los trópicos y subtrópicos. Presenta tres grandes centros de diversidad (Tryon \& Tryon 1973): uno en América (desde la zona EEUU-México - donde son muy abundantes- hasta los Andes); otro australiano y otro en la cuenca mediterránea (sobre todo Grecia y la Península Ibérica). También aparecen en el sureste africano. Cheilanthes glauca es endémica del centro-sur templado de Argentina y Chile (Ponce et al. 2002).

Ambas especies son saxícolas, se desarrollan en grietas de laderas expuestas, hasta aproximadamente los $1700-1800 \mathrm{~m}$.

Trabajos anteriores sobre gametófitos de Pleurosorus rutifolius (R.Br.) Fée (Stokey 1960; Atkinson 1973), señalan su semejanza con los pubescentes de Asplenium, y refieren datos acerca del tipo de pelos que presenta. Sobre Pleurosorus papaverifolius se conocen trabajos previos sobre la morfología de sus esporas (Salvo et al. 1982; Tryon \& Lugardon 1990). Los gametófitos de Cheilanhtes han

\footnotetext{
1 Universidad Complutense de Madrid, Facultad de Ciencias Biológicas, Depto. Biología Vegetal I, Madrid, España

2 Autor correspondiente: jmgabriel@bio.ucm.es
} 
sido más estudiados, sobre todo en relación con el desarrollo apógamo de esporófitos (Witthier 1965; 1970), fisiología y ecofisiología (Quirk \& Chambers 1981; Nondorf et al. 2003; Palmieri \& Swatzell 2004) y morfología y desarrollo (Pangua \& Vega 1996), al igual que las esporas de algunas especies (Knobloch 1969; Tryon \& Tryon 1973; Tryon \& Lugardon 1990).

Nos proponemos en el presente trabajo estudiar la fase gametofítica de los helechos rupícolas sudamericanos Pleurosorus papaverifolius y Cheilanthes glauca, desde la germinación de las esporas hasta el análisis de la expresión sexual, incluyendo una descripción de las esporas de ambas especies.

\section{Material y métodos}

Las esporas empleadas en este estudio fueron obtenidas de esporófitos recolectados en fisuras de roca expuestas, en la misma localidad. Pleurosorus papaverifolius (Kunze) Fée: Argentina, Chubut, Camino de Trevelín al paso internacional de Futalerfú, km 68, pr. al límite con Chile. 20/nov/2006, C. Prada A126 \& C. Lavalle. Cheilanthes glauca (Cav.) Mett.: idem, C. Prada A129 \& C. Lavalle. Se han depositado ejemplares testigo en el herbario de la Universidad Complutense de Madrid (Biológicas), MACB.

Las esporas de cada especie se obtuvieron de un solo esporófito, mantenido seco a temperatura ambiente desde que fue recolectado en el campo.

Para el estudio de las esporas se realizaron preparaciones en DePex. En el microscopio óptico se observó la superficie de la espora y se midió la longitud de 30 esporas de cada muestra.

Para el estudio de los gametófitos se realizaron cultivos multisporos de cada especie en agar mineral preparado según Dyer (1979), agitando una pinna fértil sobre un papel de pesar y transvasando las esporas así obtenidas a las placas petri. La siembra de cada muestra se replicó dos veces.

Los gametófitos crecieron en placas Petri de $6 \mathrm{~cm}$ de diámetro, bajo luz fluorescente en ciclos de 12 horas de luz-oscuridad, a $20 \pm 2{ }^{\circ} \mathrm{C}$.

Los porcentajes de germinación se obtuvieron de una muestra aleatoria de 50 esporas de cada placa, cada tres días hasta que no hubo más incremento. Se entendió como espora germinada aquella que manifestó emergencia del primer rizoide.

Semanalmente se tomaron muestras aleatorias para el estudio de las diferentes fases de desarrollo de los gametófitos, desde la germinación de la espora hasta la madurez sexual. Los gametófitos extraídos de las placas fueron teñidos con hidrato de cloral-acetocarmín (Edwards \& Miller 1972), montados en agua y observados en un microscopio óptico. También se realizaron observaciones en vivo. El mismo procedimiento se siguió para el estudio de las formas sexuales, gametangios y expresión sexual. El cálculo porcentual de la expresión sexual se obtuvo observando los gametangios de 30 gametófitos de cada muestra aleatoria preparada.

Para la preparación de las láminas, se tomaron fotografías con una cámara Nikkon Coolpix MDC instalada en el microscopio y, tras calcular la escala en función del aumento del microscopio y de la ampliación del objetivo de la cámara, se montaron en un programa de edición de imágenes.

\section{Resultados}

Las esporas de Pleurosorus papaverifolius son monoletes, elipsoidales o algo redondeadas, de (45)50(55) $\mu \mathrm{m}$ de longitud, con escasos pero largos e irregulares pliegues anchos. Las esporas de Cheilanthes glauca son triletes, globosas, de (70)75(80) $\mu \mathrm{m}$ de diámetro. La superficie es rugulada (Fig. 1).

Las esporas de Pleurosorus papaverifolius fueron recolectadas un mes antes de su siembra, mientras que las de Cheilanthes glauca lo fueron casi un año. Hacia el final de la primera semana tras la siembra hubo señales de germinación en los cultivos de Pleurosorus papaverifolius, pues bastantes esporas se desprendieron de su cubierta, poniendo de manifiesto una célula translúcida. Hacia el octavo día, alrededor del $5 \%$ de las esporas ya tenían rizoides manifiestos. El máximo porcentaje de germinación alcanzado fue del $73 \%$, medido casi tres semanas después de la siembra. Cheilanthes glauca tardó más en mostrar germinación, pues lo hizo hacia el final de la segunda semana tras la siembra, en el duodécimo día, pero se mostró más vigorosa, contabilizándose entonces un $43 \%$ de esporas con rizoides. El máximo porcentaje de germinación, un $72 \%$, se midió transcurridas prácticamente cinco semanas después de la siembra. La Tab. 1 y la Fig. 2 resumen los resultados obtenidos con respecto a la germinación de ambas especies.

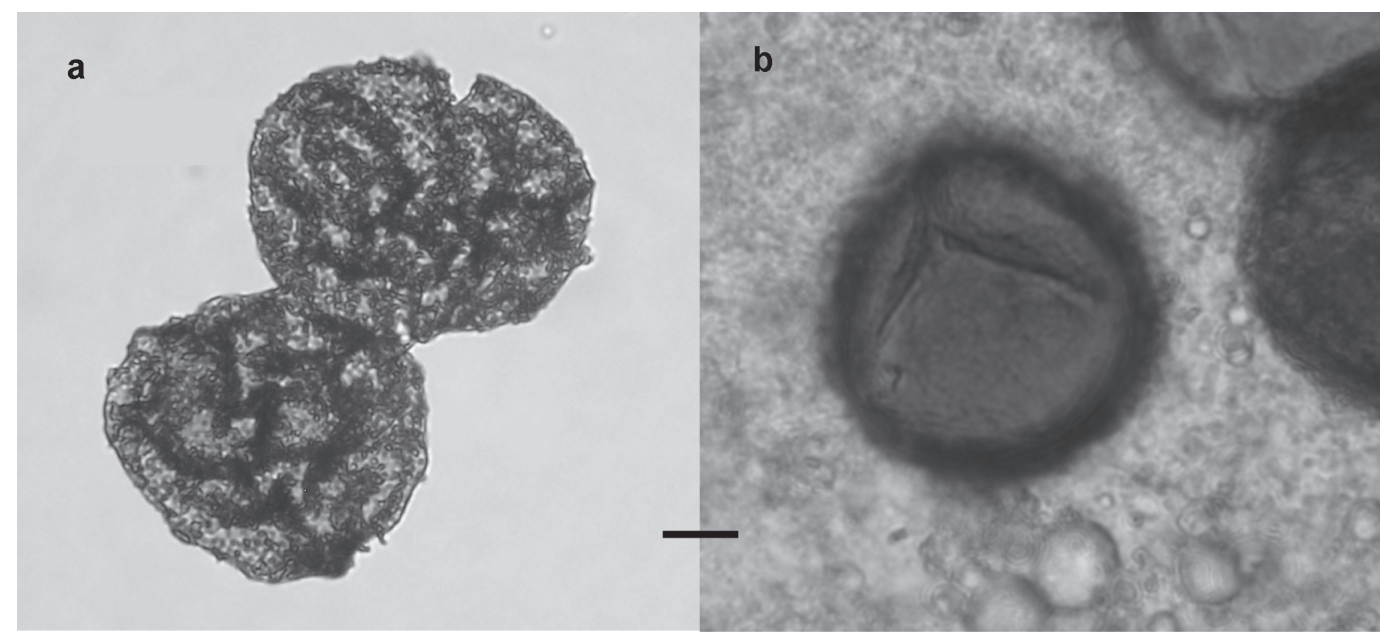

Figura 1. Esporas de las especies estudiadas, al microscopio óptico, secas y montadas en DePex. a. Esporas de Pleurosorus papaverifolius (Kunze) Fée. b. Esporas de Cheilanthes glauca (Cav.) Mett. 
Tabla 1. Datos sobre la germinación de las esporas de las especies estudiadas, cultivadas en agar mineral y mantenidas en cámara de cultivo bajo luz fluorescente en ciclos de 12 horas de luz-oscuridad, a $20 \pm 2{ }^{\circ} \mathrm{C}$.

Semanas trascurridas entre:

\begin{tabular}{lcccc}
\cline { 2 - 5 } Muestra & Recolección y siembra & Siembra y $1^{\text {a }}$ germinación & $1^{\text {a }}$ germinación y \% máx & $\%$ máximo de germinación \\
\hline Pleurosorus papaverifolius (Kunze) Fée & 4 & 1 & 1,5 & 73 \\
Cheilanthes glauca (Cav.) Mett. & 50 & 1,8 & 3 & 72
\end{tabular}

La germinación de las esporas es similar en ambas especies, pues la primera célula protálica surge de forma perpendicular a la rizoidal (Fig. 3a y f).

En Pleurosorus papaverifolius la fase filamentosa es bastante larga y de crecimiento lento, pues se prolongó por espacio de 9-11 semanas; el filamento consiste en unas 4-8 células, que son gruesas y redondeadas, dando un aspecto algo globoso al protalo; los filamentos se ramifican habitualmente por debajo de la célula apical, llegando la ramificación a ser densa (Fig. 3b). Hacia la semana 11-12, la célula apical diferencia un pelo que limita el crecimiento filamentoso, dando origen a la forma planar. El protalo comienza dividiendo el ápice hasta alcanzar varias células de grosor; en este ápice desarrolla un meristema en posición terminal.

En Cheilanthes glauca la fase filamentosa es efímera y corta, de unas 3-5 células. Rápidamente, dentro de las 2-3 primeras semanas desde la siembra, la célula apical del filamento se divide longitudinalmente, formando al poco un protalo de varias células de anchura, que rápidamente da paso al crecimiento planar. La zona meristemática ha quedado formada en el ápice del protalo (Fig. 3g), al principio situada en posición levemente lateral (Fig. 3h), por fin centrada entre las dos alas.

Las formas bidimesionales son similares en ambas especies, con la diferencia de que en Cheilanthes glauca se alcanza mucho antes. Otra diferencia que se aprecia es que el gametófito de Pleurosorus papaverifolius comienza, en esta fase, a desarrollar pelos clavados tanto en los

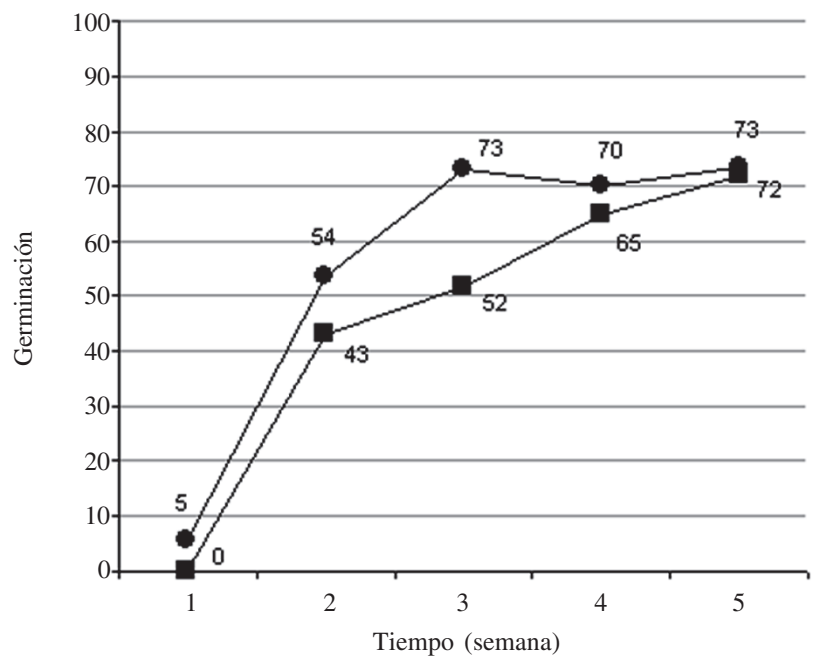

Figura 2. Porcentajes de germinación de Pleurosorus papaverifolius (Kunze) Fée (•) y Cheilanthes glauca (Cav.) Mett. (•) a lo largo de semanas consideradas tras la siembra, hasta alcanzar su máximo. márgenes de las alas como en la superficie abaxial del protalo, aunque luego aparecen también en la superficie adaxial (Fig. 3e); los pelos superficiales presentan una mayor variación en el tamaño que los marginales. Cheilanthes glauca presenta gametófitos desnudos. Otro carácter particular que queremos señalar es la presencia, en los protalos de Cheilanthes glauca, de rizoides cocleariformes que van surgiendo con frecuencia a lo largo de esta fase de desarrollo (Fig. 3j).

Los gametófitos alcanzan su forma adulta aproximadamente a las 15-20 semanas desde la siembra en Pleurosorus papaverifolius y a las 4-5 semanas en Cheilanthes glauca. En Pleurosorus papaverifolius se pueden apreciar dos formas básicas (Fig. 3c y d): los gametófitos tienden a adoptar inicialmente una forma cordada, de anchura y longitud similares, con una clara escotadura y las alas simétricas; algunos protalos retienen esta forma como definitiva, pero muchos siguen creciendo y terminan siendo unas 2-3 veces más largos que anchos; estos protalos alargados, no obstante, suelen terminar en una escotadura más o menos pronunciada. Cheilanthes glauca presenta gametófitos cordados típicos, menos variables en su forma, con alas simétricas y una escotadura clara, aunque en ocasiones pueda pasar desapercibida (Fig. 3i).

Alcanzada la forma adulta, ambas especies desarrollan gametangios, siempre en la superficie abaxial del protalo (Fig. 4). Cheilanthes glauca presenta órganos sexuales de morfología y disposición típicas. Pleurosorus papaverifolius, por el contrario, desarrolla anteridios por toda la lámina, no solo en la zona posterior del protalo, habiéndose detectado también marginales. Es reseñable, asimismo, la existencia de dos modelos de anteridios: unos sencillos, abundantes por toda la lámina, y otros que, en grupos de dos, a veces de tres, comparten su célula basal. Estos últimos son más frecuentes en la zona de los rizoides. Se ha observado, también, aunque raramente, la presencia de gametófitos masculinos precoces, que desarrollan anteridios en estado precordado.

Pleurosorus papaverifolius comienza su desarrollo sexual hacia la semana 17 tras la siembra (Fig. 5). En los primeros momentos se forma una elevada proporción de protalos masculinos, de hasta el $80 \%$. Este porcentaje tiende a disminuir en las semanas subsiguientes, hasta el final del periodo de observaciones (semana 23 después de la siembra), al tiempo que aumenta el número de protalos bisexuales, que pasa de un 3,5\% a prácticamente el 50\% hacia la semana 23. Aspectos reseñables son, por un lado, 


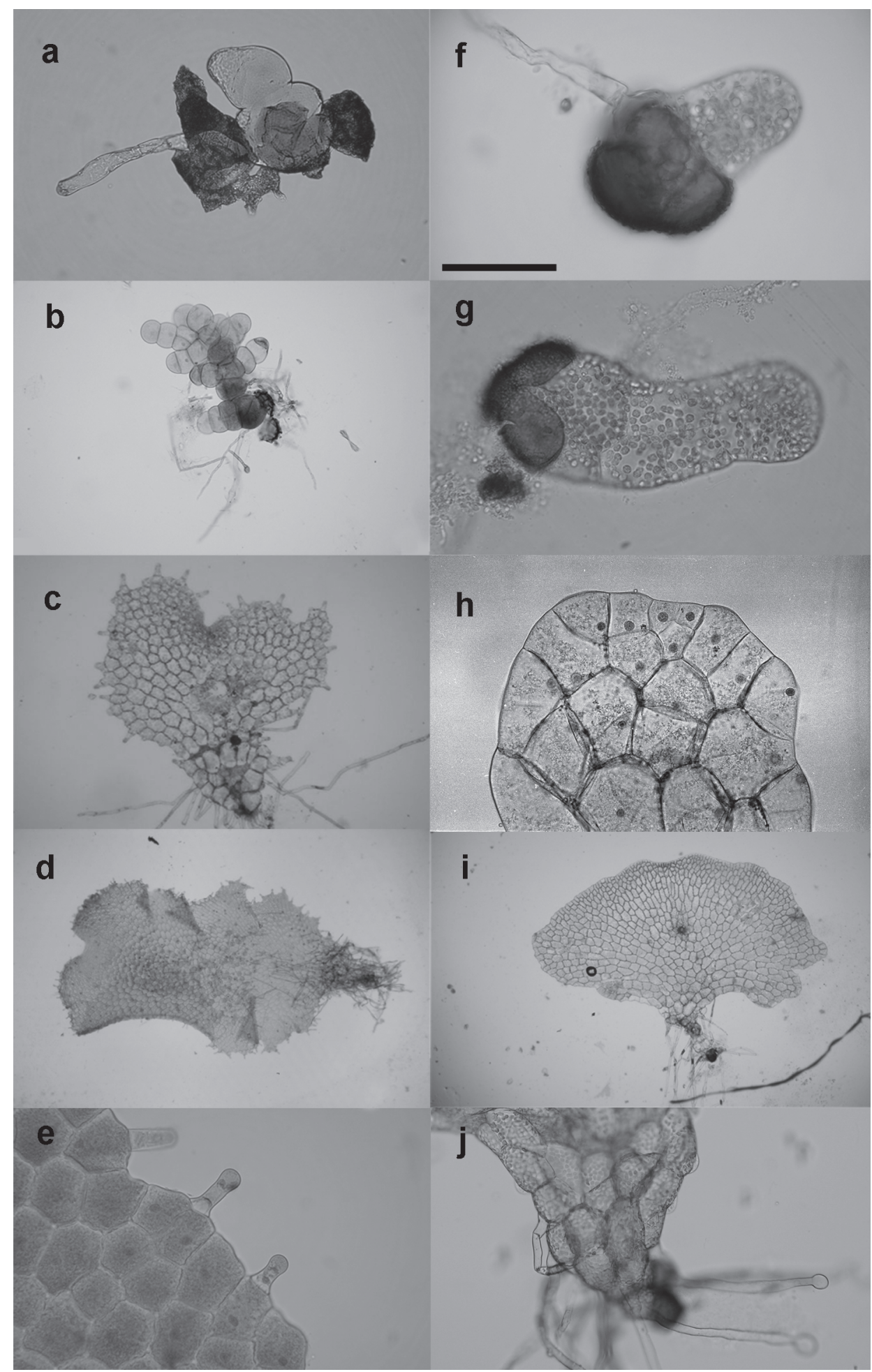

Figura 3. Principales fases y caracteres en el desarrollo de los gametófitos. Pleurosorus papaverifolius (Kunze) Fée: a. Espora germinada (1 semana). b. Crecimiento filamentoso, con protalo profusamente ramificado (5 semanas). c. Gametófito cordado adulto (15 semanas). d. Gametófito alargado adulto (20 semanas). e. Detalle de los pelos marginales (20 semanas). Cheilanthes glauca (Cav.) Mett.: f. Espora germinada (1,5 semanas). g. Ápice del filamento, con varias células de grosor, mostrando la diferenciación de las primeras células meristemáticas ( 3,5 semanas). h. Primeros estadios de la fase planar, mostrando un desarrollo algo asimétrico (4 semanas). i. Gametófito cordado adulto, sin escotadura manifiesta (4,5 semanas). j. Detalle de rizoides cocleariformes (4 semanas). El tiempo ha sido medido desde la germinación. 
la persistencia de un pequeño porcentaje de gametófitos estériles (sobre el 10\%) y, por otro, la ausencia de gametófitos femeninos.

Por su parte, Cheilanthes glauca presenta un desarrollo sexual muy rápido (Fig. 5), pues hacia la semana 5 después de la siembra comienza a producir gametangios. Se producen en primer lugar protalos arquegoniados, en un $18 \%$, porcentaje que apenas varía en las semanas subsiguientes. En la semana 7 hay un descenso muy notable de los protalos estériles a favor de un desarrollo de gametófitos masculinos, que alcanzan el $70 \%$ de la población. Este porcentaje tampoco varía mucho con el tiempo. Hacia la semana 11 tras la siembra, final del periodo de observaciones, se detectó un pequeño porcentaje (4\%) de gametófitos bisexuales y también en este caso persistía un pequeño conjunto de gametófitos estériles.

\section{Discusión}

Las observaciones realizadas tanto en tamaño como en ornamentación de las esporas de Pleurosorus papaverifolius y de Cheilanthes glauca caen dentro de los márgenes de variación previamente definidos para los respectivos géneros (Salvo et al. 1982; Tryon \& Lugardon 1990).
El patrón de germinación de las esporas de ambas especies es del tipo Vittaria definido por Nayar \& Kaur (1971), el más común entre los helechos homospóreos, según los mismos autores. Atendiendo a este patrón de desarrollo, la primera célula protálica, y por tanto el subsiguiente filamento, se forma de manera perpendicular al primer rizoide aparecido antes.

En Pleurosorus papaverifolius se observa un desarrollo del gametófito que se ajusta al modelo tipo Aspidium descrito por Nayar \& Kaur (1969): el filamento, alcanzado un tamaño de unas 8 células, limita su crecimiento por la formación de un pelo apical. Los mismos autores indican que éste suele ser el modelo normal de crecimiento en la familia Aspleniaceae, al menos entre las especies con gametófitos pelosos. No obstante, no se ha encontrado en la literatura casos de gametófitos que pasaran un largo periodo en forma de filamento ramificado previo al desarrollo bidimensional.

El patrón de desarrollo del gametófito de Cheilanthes glauca es intermedio entre el modelo Adiantum, en el que se forma una célula obcónica apical en el filamento, y el modelo Ceratopteris, en el que el meristema se forma en el gametófito bidimensional, a partir de células no marginales (Nayar \& Kaur 1969). En la especie estudiada, el meristema

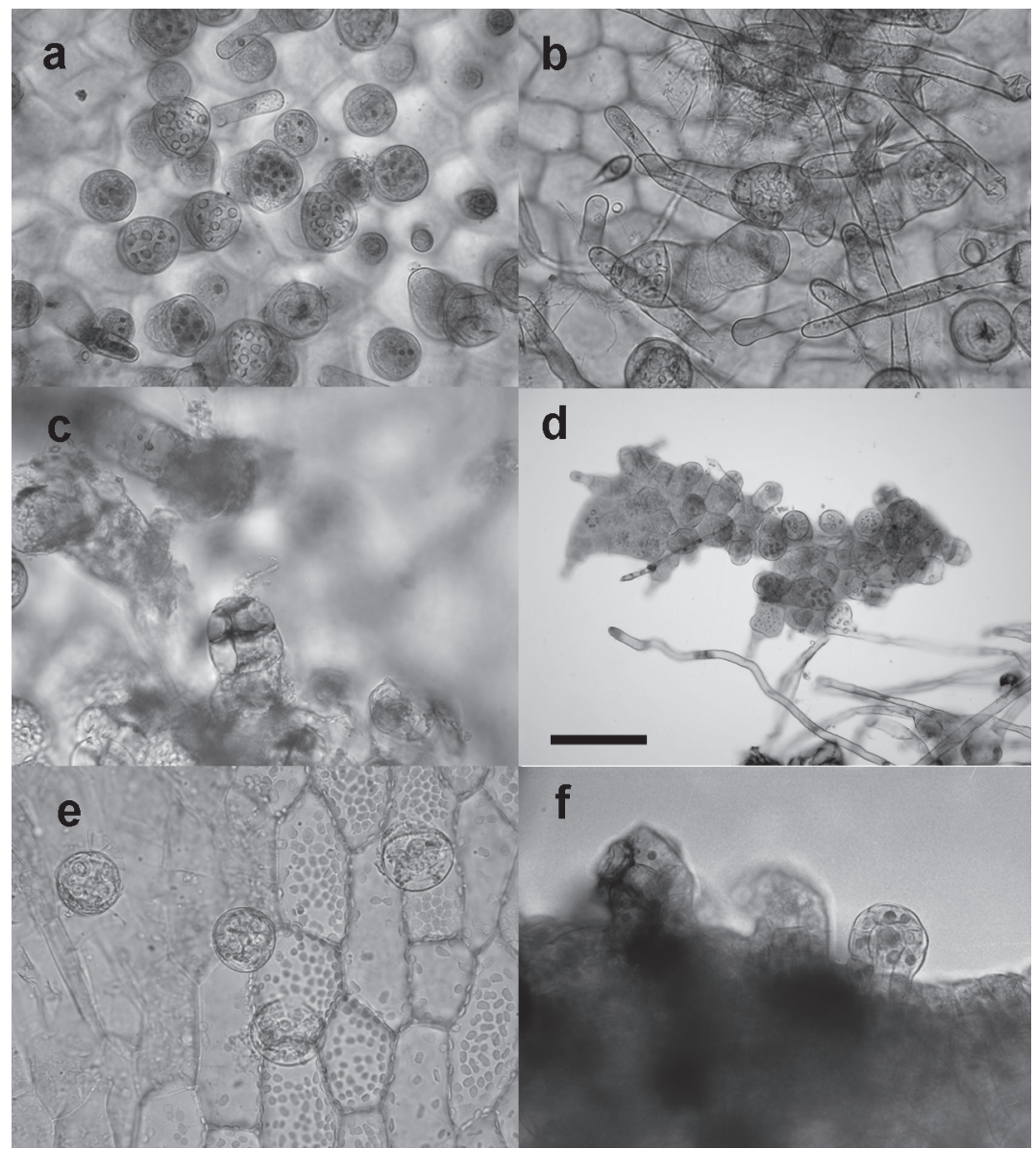

Figura 4. Órganos sexuales. Pleurosorus papaverifolius (Kunze) Fée: a. Anteridios sencillos. b. Anteridios dobles, con célula basal compartida. c. Arquegonios. d. Gametófito masculino precoz. Cheilanthes glauca (Cav.) Mett.: e. Anteridios. f. Arquegonios. 

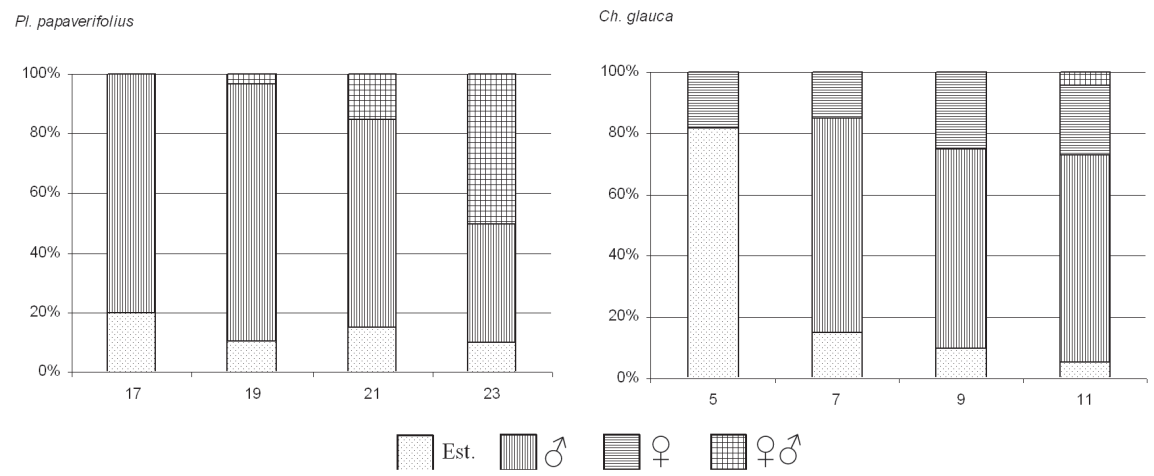

Figura 5. Evolución de la expresión sexual, en porcentajes, a lo largo de las semanas consideradas.

se forma en el gametófito bidimensional pero a partir de una célula apical. El protalo puede ser algo asimétrico en su comienzo, pero dada la posición apical del meristema, termina por formar alas simétricas. Este tipo de variaciones sobre el patrón Adiantum o Adiantum-Ceratopteris ya han sido estudiadas en varias otras especies de Cheilanthes, como Cheilanthes aemula Maxon, Cheilanthes leucopoda Link, Cheilanthes meifolia Eaton (Nayar \& Kaur 1969), Cheilanthes tinaei Tod. y Cheilanthes acrostica Tod. (Pangua \& Vega 1996), y parece ser la forma normal de desarrollo en el género, mientras que los modelos típicos son infrecuentes (Nayar \& Kaur 1969).

En lo que atañe al indumento, Pleurosorus papaverifolius presenta pelos papilados marginales y superficiales de desarrollo temprano, al igual que sucede en Pleurosorus rutifolius (Atkinson 1973), hecho que los aproxima a los gametófitos pelosos de Asplenium. En Pleurosorus rutifolius también se ha señalado la presencia, en la costilla media y entre los arquegonios, de largos pelos bicelulares con el ápice alargado (Atkinson 1973), carácter que no exhibe Pleurosorus papaverifolius. Por su parte, en numerosas floras y tratados se afirma que los gametófitos de Cheilanthes y otros géneros cheilantoides son glabros, cosa que ocurre en Cheilanthes glauca, y que la presencia de indumento es rara (Tryon 1990). Se conocen gametófitos con pelos o glándulas farinosas (Giauque 1949), al parecer relacionados con la protección del gametófito contra la desecación (Palmieri \& Swatzell 2004).

Windham \& Yatskievych (2003) señalan que el rápido desarrollo de los gametófitos es un patrón de comportamiento normal en los helechos cheilantoides, en relación con aquellos que presentan un desarrollo apógamo de los esporófitos. En Cheilanthes glauca se ha observado una gran rapidez en el desarrollo de los gametófitos y de los órganos sexuales y, sin embargo, no parece ser una especie apógama. Especies europeas como Cheilanthes tinaei y Cheilanthes acrostica, tampoco apógamas, presentan sin embargo un desarrollo más lento que Cheilanthes glauca (Pangua \& Vega 1996).

Pleurosorus papaverifolius muestra un desarrollo sexual tendente a formar, en primera instancia, una fuerte proporción de gametófitos masculinos que van con el tiempo desarrollando arquegonios, pasando a ser, por tanto, bisexuales. No se conocen estudios previos de la expresión sexual de otras especies del género, pero sí se conocen otras especies de Asplenium, como A. ruta-muraria L., en las que tampoco se desarrollan gametófitos femeninos (Pangua et al. 1994) o A. fontanum (L.) Bernh. y A. obovatum Viv., en las que éstos se forman tardíamente o en muy baja proporción (Herrero et al. 2002).

La evolución de la expresión sexual en Cheilanthes glauca se ajusta a los resultados obtenidos en otras especies (Pangua \& Vega 1996): hay una clara propensión a formar poblaciones con un elevado número de gametófitos masculinos y algunos pocos femeninos; con el tiempo van apareciendo gametófitos bisexuales a partir de gametófitos unisexuados, fundamentalmente de los masculinos.

Se podría afirmar, en principio, que las estrategias reproductivas de ambas especies estudiadas parecen encaminadas a asegurar una fecundación cruzada. La presencia de gametófitos bisexuales en los que coexisten ambos gametangios lleva a pensar que se tiende a la autofecundación, aunque también sería posible la fecundación cruzada entre gametófitos. Sin embargo, una masiva presencia de gametófitos masculinos en la población parece ser indicativo de intentos de fecundación cruzada (Klekowski 1969; Lloyd 1974), sobre todo si los gametófitos bisexuales sólo se originan pasado un cierto tiempo. No obstante, como señalan Pangua et al. (1994), la ausencia de gametófitos femeninos, como ocurre en Pleurosorus papaverifolius, parece revelar que es más probable la ocurrencia de una fecundación intragametofítica.

Atendiendo a nuestros resultados, se puede desprender que no existe correlación entre el hábitat donde viven estos helechos (fisuras de rocas), la morfología del gametófito y su patrón de desarrollo. Pleurosorus papaverifolius presenta un desarrollo más lento que Cheilanthes glauca, tanto en la adquisición de la forma adulta como en la génesis de estructuras sexuales y, por lo tanto, en el desarrollo de la subsiguiente generación esporofítica. Tampoco parecen coincidir las estrategias reproductivas: mientras que Pleurosorus papaverifolius parece tendente a la 
autofecundación de cada gametófito, lo que le daría una alta capacidad de colonización, Cheilanthes glauca muestra una mayor propensión a la fecundación cruzada. Habrá que comprobar si estos patrones de comportamiento analizados en condiciones de laboratorio son similares en sus ambientes naturales.

\section{Agradecimientos}

Los autores agradecen a la Agencia Española de Cooperación Internacional (AECI, proyecto A 6307/06) y a la Universidad Complutense de Madrid (España) el apoyo recibido para la realización de este trabajo.

\section{Referencias bibliográficas}

Atkinson, L.R. 1973. The gametophyte and family relationships. Botanical Journal of the Linnean Society 67(suppl. 1): 73-90.

Christ, H. 1910. Die Geographie der Farne. Jena.

Dyer, A. 1979. The culture of fern gametophytes for experimental investigation. Pp. 254-305. In: A. Dyer (ed.). The Experimental Biology of Ferns. London, Academic Press.

Edwards, M.E. \& Miller, J.H. 1972. Growth regulation by ethylene in fern gametophytes III. Inhibition of spore germination. American Journal of Botany 59: 458-465.

Giauque, M.F.A. 1949. Wax glands and prothallia. American Fern Journal 39: 33-35.

Given, D.R. 1972. Pleurosorus rutifolius (R.Br.) Fee (Aspleniaceae) in New Zealand. New Zealand Journal of Botany 10: 495-506.

Herrero, A.; Prada, C. \& Pajarón, S. 2002. Gametophyte morphology and gametangial ontogeny of Asplenium foreziense and related taxa (Aspleniaceae: Pteridophyta). Botanical Journal of the Linnean Society 139: 87-98.

Klekowski, E.J. Jr. 1969. Reproductive biology of the Pteridophyta II. Theoretical considerations. Botanical Journal of the Linnean Society 62: 347-359.

Knobloch, I.W. 1969. The spore pattern in some species of Cheilanthes. American Journal of Botany 56: 646-653.

Kramer, K.U. 1993. Distribution patterns in major pteridophyte taxa relative to those of angiosperms. Journal of Biogeography 20: 287-291.

Lloyd, R.M. 1974. Reproductive biology and evolution in the Pteridophyta. Annals of the Missouri Botanical Garden 61: $318-331$.

Nayar, B.K. \& Kaur, S. 1969. Types of prothallial development in homosporous ferns. Phytomorphology 19: 171-188.

Nayar, B.K. \& Kaur, S. 1971. Gametophytes of homosporous ferns. The Botanical Review 37: 295-396.
Nondorf, S.L.; Dooley, M.A.; Palmieri, M. \& Swatzell, L.J. 2003. The effects of $\mathrm{pH}$, temperature, light intensity, light quality, and moisture levels on spore germination in Cheilanthes feei of Southeast Missouri. American Fern Journal 93: 56-69.

Palmieri, M. \& Swatzell, L.J. 2004. Mycorrhizal fungi associated with the fern Cheilanthes lanosa in southeast Missouri and southern Illinois. Northeastern Naturalist 11: 57-66.

Pangua, E.; Lindsay, S. \& Dyer, A. 1994. Spore germination and gametophyte development in three species of Asplenium. Annals of Botany 73: 587-593.

Pangua, E. \& Vega, B. 1996. Comparative study of gametophyte development in Cosentinia and Anogramma (Hemionitidaceae) and Cheilanthes (Sinopteridaceae). Pp. 497-508. In: J.M. Camus; M. Gibby \& R.J. Johns (eds.). Pteridology in Perspective. Kew, Royal Botanic Gardens.

Ponce, M.; Mehltreter, K. \& de la Sota, E.R. 2002. Análisis biogeográfico de la diversidad pteridofítica en Argentina y Chile continental. Revista Chilena de Historia Natural 75: 703-717.

Quirk, H. \& Chambers, T.C. 1981. Drought tolerance in Cheilanthes with special reference to the gametophyte. Fern Gazette 12: 121-129.

Rodriguez, R. 1976. Geographic distribution of the fern Pleurosorus papaverifolius in America. Boletín de la Sociedad de Biología de Concepción 49: 79-86.

Salvo, A.E.; Prada, C. \& Díaz, T. 1982. Revisión del género Asplenium L. subgénero Pleurosorus (Fée) Salvo, Prada \& Díaz. Candollea 37: $457-482$

Stokey, A.G. 1960. Multicellular and branched hairs on the fern gametophyte. American Fern Journal 50: 78-87.

Tryon, R.M. 1990. Pteridaceae. Pp. 230-256. In: K.U. Kramer \& P.S. Green (eds.). The families and genera of vascular plants. Volume I: Pteridophytes and Gimnosperms. Berlin, Springer.

Tryon, A.F. \& Lugardon, B. 1990. Spores of the Pteridophyta. New York, Springer.

Tryon, R.M. \& Tryon, A.F. 1973. Geography, spores and evolutionary relations in the Cheilantoid ferns. Botanical Journal of the Linnean Society 67(suppl. 1): 145-153.

Villagrán, C. \& Mesa, A. 1971. Sobre dos variedades nuevas de Pleurosorus papaverifolius (Kunze) Fée encontradas en la provincia de Valparaíso. Boletín del Museo de Historia Natural 32: 371-376.

Windham, M.D. \& Yatskievy, G. 2003. Chromosome studies of cheilanthoid ferns (Pteridaceae: Cheilanthoideae) from the western United States and Mexico. American Journal of Botany 90: 1788-1800.

Witthier, D.P. 1965. Obligate apogamy in Cheilanthes tomentosa and C. alabamensis. Botanical Gazette 126: 275-281.

Witthier, D.P. 1970. The initiation of sporophytes by obligate apogamy in Cheilanthes castanea. American Journal of Botany 57: 1249-1254. 